Goldschmidt 2021 Abstract

https://doi.org/10.7185/gold2021.5755

\section{Super critical fluids in quartz phenocrysts of porphyritic granitic dyke in the Dongping gold deposit, Northern China}

\author{
JIUHUA XU ${ }^{1}$, HAIXIA CHU ${ }^{2}$, DEPING CHEN ${ }^{1}$, HAO WEI ${ }^{3}$ \\ AND GUORUI ZHANG ${ }^{4}$ \\ ${ }^{1}$ University of Science and Technoloy Beijing \\ ${ }^{2}$ China University of Geosciences (Beijing) \\ ${ }^{3}$ Hebei GEO university \\ ${ }^{4}$ East China University of Technology, Nanchang \\ Presenting Author: jiuhuaxu@126.com
}

The giant Dongping gold deposit, hosted in alkaline igneous intrusions, is the first deposit of this kind discovered among the alkaline complex-hosted gold ores in China. In this deposit, a newly found porphyritic granitic dyke along a NEE-SWW striking shear zone and contains abundant quartz phenocrystals (Fig.1).

Fluid inclusion study indicate that the fluids in quartz phenocrystals can be approximated as medium to high temperature hydrothermal and low salinity $\mathrm{H}_{2} \mathrm{O}-\mathrm{CO}_{2}-\mathrm{NaCl}$ fluids. The coexistence of $\mathrm{V}$-only and $\mathrm{L}+\mathrm{V}$ inclusions with variable vapour/liquid ratios may indicate fluid immiscibility during the forming of the quartz phenocrysts. Melt inclusions are occasionally observed in quartz phenocrysts. We selected two pieces of thin sections containing suspected melt inclusions and put them into two cucibles and heated in the muffle from $25^{\circ} \mathrm{C}$ to $800^{\circ} \mathrm{C}$ with $10^{\circ} \mathrm{C} / \mathrm{min}$ of temperature increasing rate, and then stay at $800^{\circ} \mathrm{C}$ for 10 hours. Then, these thin sections were quenched in open air under $25^{\circ} \mathrm{C}$, and no obvious change was observed under microscope. They were heated again in the maffle with the same heating rate until $1000^{\circ} \mathrm{C}$ reached, and then remaining this temperature in 10 hours before quenching. The phases were changed during this period and only glassic homogenized phase can be seen in the inclusion (fig.2). It is indicated that melt inclusions could be existed in quartz phenocrysts. We inferred that the original fluid during formation of porphyritic granite could be a super critical fluid or a meltfluid mixture (Xiao et al., 2015).

When the temperatures and pressures in the system reach the upper critical point, aqueous solution and silicate melt become one phase of complete miscibility, which can be called as supercritical fluids. Previous studies show that the upper critical point of $\mathrm{SiO}_{2}-\mathrm{H}_{2} \mathrm{O}$ system has pressure of $1.0 \mathrm{GPa}$ and temperature of $1080^{\circ} \mathrm{C}$. The P-T conditions of ZZL porphyritic granite were closed to the upper critical points of mentioned acid aqueous-melt systems. According to zircon U-Pb dating and ArAr ages of orthoclase, the ZZL porphyritic granite might be originated from residual of Jurassic granitie intrusion in the south of mine area.
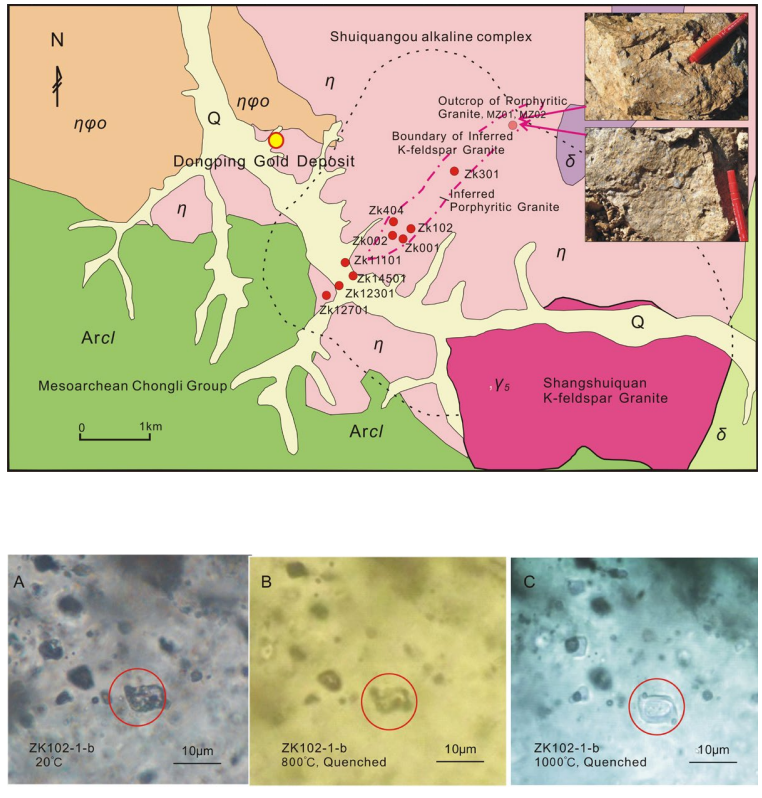